\title{
Application Research on Power Demand Side Management in Energy Saving Service for Consumers
}

\author{
Liu Xiangxiang \\ Power Research Institute of State Grid Jiangxi Electric Power Company
}

\begin{abstract}
Keywords: Power demand side management; Power enterprises; Energy saving service for power consumers; Method
\end{abstract}

\begin{abstract}
With the economic and social development, power marketing model is also constantly changing, the social responsibility of power enterprises is being continuously enhanced, and power customers have higher and higher standards for the energy saving service. Under the shortage of energy resources, it is the responsibility of power enterprises to carry on the reasonable using of resources and increase the electric power efficiency of the customers. In electric power customer service, it is a new issue for power enterprises under new situations how to adapt to the opportunities and challenges followed by the reform as soon as possible and change the traditional concept and model in order to further improve the electric power customer service and management level, carry out the dynamic management, improve the electricity utilization efficiency and improve the customer satisfaction. At the same time, it is also an important mission to promote the sustainable development of power enterprises and customers and the sustainable social development. Thus, in order to improve the service level of power enterprises, this paper introduces the roles and characteristics of power demand side management and proposes the countermeasures aiming at the problems of power demand side management existed in electric power customer service.
\end{abstract}

\section{Introduction}

With the rapid development of the market economy, the competition between power enterprises has become more intense. As the terminal link of operation of power enterprises, customer service not only can be used to check the fitness of the internal management of power enterprises and enterprises' development, but also can influence the fate and future of power enterprises. Therefore, it is the main source of power enterprises' competence to provide outstanding service and improve the management level of electric power customer service. At the same time, in the situation of society environmental stress and resource shortage, it is also the responsibility of power enterprises to strengthen the sense of social responsibility, reasonably plan and use resources and finally optimize the benefit. Therefore, to carry out the dynamic management, improve the customer service level, improve the power consumption efficiency and promote the transformation and upgrading of power enterprises, the research and application of power demand side management should be strengthened to fully play its important role in the customer service. This paper emphasizes the importance of power demand side management in the work of electric customer service. In the current situations, in order to improve the power user management quality and enhance the leading position of the sense of social responsibility in power marketing, the dynamic management for the work of electric customer service should be carried out with the power demand side management as the main content to constantly improve the management level and performance of power marketing.

\section{The Relationship Between Power Demand Side Management and Customer Service}

Customers are the most important people for enterprises forever. The aim of customer service is to form the personally pleasing memorable interaction (PPMI) between the enterprises and the customers. In the interactive process, the enterprises increase the customers satisfaction and emphasize their importance based on the customers preferences, and the customers remember and 
keep in touch with the enterprises all the time. As a new electric management mechanism, power demand side management is refer to one kind of power consumption management activity, by taking effective measures, which optimizes power consumption way, improves power consumption efficiency, optimizes the allocation of resources, improves and protects the environment and reduces the cost. The demand in power of our society is operation guide of the power enterprises, and the balance between supply and demand in power is the basic task of power enterprises. Therefore, power demand side management should be fully involved in the work of electric power customer service. Demand side management (DSM) will help the power enterprise change to the service enterprises, emphasize the partnership between the power enterprises and the customers and emphasize the energy service based on customer benefits as follows:

Firstly, demand side management emphasizes the direct economic benefit based on the improvement of electric power efficiency. Demand side management is one kind of operation management activity for efficiency, benefits and energy conservation without influence on the normal production and life of customers. Any measures of demand side management should bring economic benefits for our society, the power enterprises and the customers.

Secondly, demand side management emphasizes the partnership between the power enterprises and the customers. In the past, the power customers have no choice for the electric power consumption in the demand side management. But now the demand side management has been one kind of activity the customers can consciously and freely attend. With incentive measures, the power enterprises mobilize initiative of saving electricity of the electric power customers. In demand side management, the power enterprises and the customers should be required to share the risk and benefits.

Thirdly, demand side management emphasizes the energy service based on customer benefits. The power enterprises must establish the thought of outstanding service and abandon the behaviors of forcibly restricting the use of electricity and shifting the peak load at the cost of the customers' bearing capacity and economic benefits. By taking multiple incentive policies, the power enterprises should make customers actively change their consumption behavior and electricity consumption way to improve the electric power efficiency and reduce the power demand for both improvement of the economic efficiency of power grid and reduction of electricity cost for customers.

\section{Benefits of Demand Side Management in the New Era}

\section{(1)Ensuring of Power Supply Safety.}

In the electric power field, the most important thing is power supply safety. A power accident will bring about irreparable consequences for the power enterprises. So the enterprises must ensure the power supply safety. Power supply safety refers to that the adaptation of power consumption equipment is carried out according to the industry regulations without personal safety accidence and electric accidents. An electronic enterprise mainly engaged in the package and test for discrete power devices is a good example. It has many products widely used in the major fields. But tripping and interruption of power supply phenomena usually occur during production. Through analysis with the power management system, it is the main reason that lots of harmonic disturbance is generated in operation of the compound air compressor. These harmonics will raise the temperature of transformer equipment, cause the unstable power supply, reduce service life of equipment and even bring about electric accidents.

(2) More Convenient Power Demand Management.

With the rapid development of science and technology in new era, the technological products have been widely applied in people's daily life. In this situation, for power demand side management, high and new technology has been introduced for power consumption management. With help of the management software and a computer, the power enterprises carry out the centralized management for power consumption. This is beneficial for the lookup and classification of power consumption types. The administrators just need to carry out the data comparison to find out the problems existed in power consumption for their high efficiency work. Based on the electric power data stored on a hard disk, power enterprise can build a management platform and update the 
data by making full use of the internet to ensure accuracy of the power consumption. In addition, a password should be set for the data management center to avoid the random data view and change realized by others.

(3)Orderly Power Consumption and Energy-Saving \& Emission-Reduction.

In our country, the main aim of power demand side management is orderly power consumption. Under the background of big data, the power consumption can be analyzed through power demand side management to further introduce appropriate measures for regional orderly power consumption and energy-saving \& emission-reduction.

\section{Application Method of Demand Side Management in Energy Saving Service for Power Consumers}

\section{(1)Understanding Power Requirements of the Power Consumers.}

To realize the power demand side management, the power enterprises should firstly understand the power requirements of power consumers, and grasp the electric power consumption trend of consumers by making an overall grasp of the power consumption of consumers. In power supply, the related data should be monitored, recorded and shared in each section of enterprise by the power enterprises to ensure the reality and accuracy of data. In addition, a sufficient investigation for the power market should be carried out by each power enterprise. The power enterprise can set up an investigation team to carry out market investigation work to deeply understand the power requirements and power consumption of consumers, outline the general trend of power consumption and make the scientific program for the power transmission system of power enterprises to make it meet the power requirements of consumers.

(2) Strengthening the Advertisement and Popularization of Power Demand Side Management.

In the implementation process of power demand side management, the state and power enterprises should popularize the concept of power demand side management to the power consumers hand in hand to make them understand its meaning and purpose and their own roles in the power demand side management. At the same time, the power enterprises should also strengthen the publicity of energy conservation awareness to make power consumers deeply appreciate the seriousness of energy shortage, make each consumer consciously establish the energy conservation awareness and actively participate in the power demand side management.

(3)Proper Application of Peak-Valley Time-of-Use Tariff.

In the implementation process of power demand side management, the power enterprises should take certain means to adjust the power consumption of consumers. As a practical mean to adjust the power consumption, peak-valley time-of-use tariff can control the power consumption of consumer to some extent to help the power consumers realize the rational power consumption and power conservation. The scientific power price should be formulated when the peak-valley time-of-use tariff is adopted. The peak time-of-use tariff should be lovely contrast with the valley time-of-use tariff. The peak time-of-use tariff can be formulated above four times the valley time-of-use tariff when the power price is formulated. In this way, it will make the power consumers have certain concern in power consumption due to the electricity charge. The higher peak time-of-use tariff will make the power consumers consciously adjust their time of power consuming.

\section{Conclusion}

As an important energy, electricity energy is very important for social production. In other words, no electricity energy, no social production. Nowadays, with the constantly increasing electricity energy demand in our country, it has become more important for the sustainable development to take effective measures and save electricity energy. The application of power demand side management in electric power customer service can not only save the electricity energy but also promote the development of power enterprises to provide the consumers with better service. To successfully realize the power demand side management, the power enterprises and consumers 
should cooperate with each other, and be supplementary to each other in work.

\section{References}

[1]Cook E D. Future research needs in the electrical industry[J]. Electrical Engineering, 2013, 78(11):1074-1077.

[2]Cyr T, Syal M. Applied Research Directions for the Electrical Contracting Industry[J]. Professional Constructor the Journal of the American Institute, 2014.

[3]Zhong-Dong M A, Han Y, Liang S G, et al. Research on Upgrading of Electrical Appliances Industry Cluster for Qingdao District - an Empirical Study Based on DMI Model[J]. Journal of Liaocheng University, 2015.

[4]Yang H B, Yang S G, Zhang L P, et al. Application Status and Research Progress of Silicone Rubber in Electrical Industry[J]. Silicone Material, 2016.

[5]Wang Y. Steel Industry Overcapacity Early Warning Research Based on Neural Network[C]// International Conference on Smart Grid and Electrical Automation. IEEE, 2016:160-163.

[6]Otsuka T. Sachio Imakubo, The Factory in the German Electrical Industry 1873-1904[J]. Access \& Download Statistics, 2013:376-378.

[7]Ren D H. Research Intelligent Building Electrical Energy Saving Design[J]. Intelligent Building \& Smart City, 2017.

[8]Isada F, Isada Y. An Empirical Study Of A Sustainable Strategy And Profitability In The Electrical-Manufacturing Industry[J]. Economy \& Business Journal, 2014, 8.

[9]Cheng P, Kong X, Wang G, et al. Research of a new structure of HTS DC Motor[C]// International Conference on Electrical Systems for Aircraft, Railway, Ship Propulsion and Road Vehicles. IEEE, 2015:1-5.

[10]Lee H S, Kang J O, Lee O Y, et al. Analysis on the Degradation Characteristics of 2G High-Tc Superconducting Wires in Accordance with Electrical Breakdown Voltage[J]. Advanced Materials Research, 2015, 1125(7):593-597.

[11]Hao S L, Zhang D L. The Construction Personnel Safety Risk Analysis and Risk Response of Mechanical and Electrical Installation Project[J]. Advanced Materials Research, 2014, 912-914:1809-1812.

[12]Research Group. Model on the Demands Forming Mechanism of Electrical Talents[J]. Journal of Wuhan Electric Power Technical College, 2014.

[13]Sangeetha M S, Nandhitha N M, Roslin S E. Impact of Emissivity on the Hotspot Temperature for Condition Monitoring of Electrical Equipments in Closed Room[J]. Advanced Materials Research, 2014, 984-985(984-985):1214-1219.

[14]Herrigel G. Globalization and the German industrial production model[J]. Journal for Labour Market Research, 2014, 48(2):1-17.

[15]Xue R, Chen Z, Dai H, et al. Effects of rare earth ionic doping on microstructures and electrical properties of $\mathrm{CaCu} 3 \mathrm{Ti} 4 \mathrm{O}$ 12, ceramics[J]. Materials Research Bulletin, 2015, 66:254-261. 